\title{
BMJ Global Health Dialogical reflexivity towards collective action to transform global health
}

To cite: Liwanag HJ, Rhule E. Dialogical reflexivity towards collective action to transform global health. BMJ Global Health 2021;6:e006825. doi:10.1136/ bmjgh-2021-006825

Handling editor Seye Abimbola

Received 6 July 2021 Accepted 11 August 2021

Check for updates

C Author(s) (or their employer(s)) 2021. Re-use permitted under CC BY-NC. No commercial re-use. See rights and permissions. Published by BMJ.

United Nations University International Institute for Global Health, Cheras, Federal Territory of Kuala Lumpur, Malaysia

Correspondence to Dr Harvy Joy Liwanag; hliwanag@unu.edu

\author{
Harvy Joy Liwanag (D), Emma Rhule (D)
}

\section{BACKGROUND}

The COVID-19 pandemic has shone a spotlight on existing systemic inequities, both in terms of health inequity and broader socioeconomic inequities. ${ }^{1}$ There have been calls globally not just to build back better but to do so in a way that dismantles structural inequities. ${ }^{2}$ Abimbola $e t a l^{3}$ have outlined facets of supremacy, encompassing coloniality, patriarchy, racism, white supremacy and saviourism, that together maintain power asymmetries and privilege within global health. The pushback against these inequities is perhaps most visible in the many calls to 'decolonise global health'. ${ }^{4-7}$ While there is currently no unified definition of what it would mean to decolonise global health, in its broadest sense it has been described as the 'imperative of problematising coloniality'. ${ }^{8}$ Over the past 18 months, 'decolonising global health' has gained pace as a collection of activist movements that seek to transition from the theoretical to the practical. While differing in approach ${ }^{9-11}$ they are unified by the impetus to actively deconstruct ingrained systems of power and privilege that continue to prioritise the perspectives of those from former colonial powers, persistently marginalising those with lived experience and hampering the attainment of health equity.

In the clamour for change and with the increasing political prioritisation of the decolonising agenda, there is a real risk of individuals and institutions entering the discourse in ways that are performative. ${ }^{1213}$ Actions may be motivated by their perceived ability to further the careers of individuals, bolster the reputations of institutions or simply by a desire to be seen to be 'doing something'. Reflexivity, the act of acknowledging individual positionality $^{1415}$ and motivation ${ }^{16}$ when engaging with the rhetoric on systems transformation, ${ }^{17}$ has been posited as a vital component of decolonising global health and in dismantling supremacy more broadly.

\section{Summary box}

Decolonising global health has gained momentum in recent years and has called for more reflexive individuals.

- However, the call to be reflexive may run the risk of becoming lip service without clarity on what reflexivity requires.

- We diverge from reflexivity's usual place in qualitative research, bring it closer to individual positionalities and frame it as comprising of: (a) self-understanding; (b) dialogue with peers; and (c) insights-to-action.

- We argue that reflexivity that is either in isolation or without action will not contribute to global health transformation.

- We present insights and action points from our journeys in global health to demonstrate examples of what may emerge from dialogical reflexivity as we have framed it here.

- We call on peers to build a culture of reflexivity by sparking dialogues in their institutions and translating their insights into collective action.

Our route to developing a reflexive process was sparked by conversations within and outside our institute on the prevalence of the foreign gaze and lingering colonial legacy in global health. It was also prompted, in part, by a question from a fellow low-to-middleincome country (LMIC) participant during a session on COVID-19 in a global health conference:

'As LMICs are not capable [emphasis ours] of utilising the evidence for policy decisionmaking, though they have an ample of evidence within their system, shall the WHO facilitate collaboration between LMICs and developed countries for evidence-based decision-making?'

The question was likely raised with an intent to improve the pandemic response in LMICs, but its phrasing struck a chord. The perception that LMICs need to be 'rescued' by high-income countries (HICs) still lingers even though many LMICs have performed well in managing the pandemic. ${ }^{18}$ 
The question has led us to discuss the persistence of colonial mentality, or the automatic preference, expressed either consciously or subconsciously, for anything Western. ${ }^{19}$ We cannot transform global health while people's views of what global health is remain unexamined and unchanged. For global health transformation to become more than just an academic discussion, the discourse must be relatable and made personal through reflexive dialogues between individuals across geographical, economical and epistemic divides. However, without clarity on what reflexivity concretely requires, calls to be reflexive run the risk of becoming lip service. Reflexivity cannot transform global health when it is only selfreflection or does not lead to collective action.

\section{'WESTERN' REFLEXIVITY AND LEARNING FROM INDIGENOUS PRACTICE}

In qualitative research, reflexivity has been promoted to maintain integrity as the researcher is tasked to examine how their personal characteristics such as gender, age, race, sexual orientation, ideological beliefs and the like influence the research process. ${ }^{20}$ Reflexivity, however, is not the same as reflection, where one 'thinks about something' in a distanced process; reflexivity is an immediate and continuing process of conscious self-awareness. ${ }^{21}$ The internal dialogue should also not be freewheeling, which may turn reflexivity into an unchecked process of self-centred analysis. Just because the researcher is aware of issues of inequity does not necessarily mean that these issues have been addressed. ${ }^{22}$ The reflexive researcher must 'acknowledge the importance of power at the micro-level of the self and our relationships with others, as well as at the macro-levels of society'. ${ }^{23}$ When viewed as relational, reflexivity becomes 'collective reflexivity', manifesting in collaborative counter-colonial research of reflexive individuals who are receptive to new cultural domains of understanding. ${ }^{24}$

We recognise the dominance of Western academic traditions in global health and acknowledge reflexivity as a concept that emerged from Western research methodologies. Therefore, we do not wish to propose reflexivity as the singular approach to 'decolonise the mind'. Indigenous practices of 'knowing, being, and doing' can enrich our understanding of reflexivity by bringing in the dimensions of relations and action. For example, Pidgeon ${ }^{25}$ has proposed a 'wholistic' framework that emphasises the indigenous worldview of seeing the whole person (physical, emotional, spiritual and intellectual) in relationship with other individuals, communities, nations and the world, guided by the values of respect, reciprocity, relevance and responsibility. Drawing on their work to assess the cultural safety of Australian public policy as it affects Aboriginal and Torres Strait Islander peoples, Mackean et al ${ }^{15}$ have also emphasised the aspect of accountability where reflexivity leads to responsibility for one's actions.

\section{FRAMING REFLEXIVITY IN PRACTICE}

We draw on the concept of reflexivity and highlight the wholistic worldview of indigenous practice to diverge from reflexivity's usual place in qualitative research, bring it closer to individual positionalities and frame it as comprising of the elements of: (a) self-understanding; (b) dialogue with peers; and (c) insights-to-action (table 1).

We have outlined our application of reflexivity according to these elements.

\section{Self-understanding}

First, we must acknowledge that the position we occupy in global health, whether in LMICs or HICs, is still an outcome of supremacy that continues to privilege some over others. Reflexivity begins with recognising that we have been impacted by the intersecting power asymmetries that exist and both benefitted and disadvantaged in one way or another across gradients of privilege. By acknowledging that each of us benefits from strands of privilege, we can commit to using that privilege through self-awareness to promote justice and rebalance the power in global health.

Table 1 Our proposed framing of reflexivity based on three elements after drawing on reflexivity in qualitative research and indigenous practices of knowing, being and doing

\begin{tabular}{|c|c|c|}
\hline $\begin{array}{l}\text { Selected attributes of reflexivity in } \\
\text { qualitative research }\end{array}$ & $\begin{array}{l}\text { Selected attributes of indigenous practices } \\
\text { of knowing, being and doing }\end{array}$ & $\begin{array}{l}\text { Framing 'reflexivity in practice' } \\
\text { comprising of three elements }\end{array}$ \\
\hline $\begin{array}{l}\text { A continuing process of conscious } \\
\text { self-awareness while living in the } \\
\text { moment } \\
\text { Must acknowledge power relations; } \\
\text { requires readiness for discomfort } \\
\text { Not in isolation but through dialogues } \\
\text { with others; a learning process that } \\
\text { leads to collective reflexivity } \\
\text { Primarily a Western approach; } \\
\text { must recognise other indigenous } \\
\text { approaches as equally valuable }\end{array}$ & $\begin{array}{l}\text { Wholistic approach, where the people } \\
\text { situate themselves in relation to others, the } \\
\text { community, the nation and the world } \\
\text { Maintaining relationships is essential; to } \\
\text { be reflexive is to take responsibility and } \\
\text { become accountable for actions }\end{array}$ & $\begin{array}{l}\text { 1. Self-understanding } \\
\text { 2. Dialogue with peers } \\
\text { 3. Insights-to-action }\end{array}$ \\
\hline
\end{tabular}


Second, reflexivity means looking back at our personal histories, complex as they are, and assessing patterns of both injustice and privilege. It requires leaving our comfort zones and questioning the motivations behind our actions, knowing that how we've been thinking and acting about global health has been shaped in part by the conditions created by coloniality. 'Conscious engagement with discomfort offers a fertile starting point for... making contact with the moral and political textures of our collective past, present, and future ${ }^{26}$ We propose these two guide questions:

(a) Looking back at my experiences, in what ways did strands of injustice and privilege create the conditions that have brought me to where I am today?

(b) How have my experiences, both personal and professional, influenced the way that I engage in global health?

While the proposed questions delve into personal histories, dialogical reflexivity includes situating experiences within the broader history of supremacy. With respect to decolonising global health, it should also build on the existing body of work within decolonial studies, much of which has been led by scholars and practitioners from LMICs and indigenous populations. ${ }^{27-31}$ Therefore, self-understanding cannot be separated from also understanding the context of power structures and coloniality that embody one's identity and continue to shape one's position and trajectory in global health and beyond.

\section{Dialogue with peers}

Third, we believe that self-awareness is achieved through dialogues with peers in global health (and beyond) who can offer alternative perspectives and help us manage our biases and reactivity, ${ }^{22}$ as well as provoke us to confront the colonial legacies in global health. Dialogues must also include those who do not believe in the decolonisation of global health. This is not just about creating future allies but also about exchanging viewpoints to understand the weaknesses in our arguments and iterate the solutions to address them.

\section{Insights-to-action}

Fourth, reflexivity means translating insights to action. As we become more self-aware, we must use the realisations to commit our present and future actions to dismantle power asymmetries in global health. In this way, selfawareness leads to a better appreciation of personal and collective responsibility for global health.

Guided by these steps, we present insights that emerged from our dialogues with each other in boxes 1 and 2 .

\section{WALKING TOGETHER TOWARDS TRANSFORMATION}

The insights and action points that emerged from our reflexive dialogues demonstrate examples of how others may be reflexive in their global health roles. Our experiences may be different but unified by a common reflexive approach that focuses on individual positionalities while also acknowledging the circumstances that created them.
Box 1 My global health journey from the Philippines to the West

I grew up in the Philippines where, although it was both a Spanish and American colony, the people adored America more. I grew up learning English, the language of our education system, listening to American music, watching Hollywood films, and seeing many of my relatives and friends fulfil their dreams of migrating to America. In such an environment, like many Filipinos, I have developed a tendency to view anything American as superior. However, I now think about the "Stop Asian Hate" movement and feel betrayed that our love for America has been reciprocated with racism and violence. It still is a colonial relationship.

I attended a private university in Manila where, influenced by the school's call to service, I joined a group of students who spent weekends in the slums and taught kids science lessons. I think of that time and see nothing wrong with my motivation, except that I realise today that the lives of the people there have not improved while I, on the other hand, have advanced in my professional trajectory, partly aided by my privileged position in society. I think about how much my country has a long way to go towards achieving equal opportunity for all.

I had the opportunity to do my PhD in Europe, thanks to a scholarship program by the Swiss government, for which I am always grateful. I think about our classroom discussions and realise that LMICs have often been the examples for addressing global health problems. I then think about the problems of developed countries too. In a decolonised global health course, wouldn't the challenges of the UK National Health Service be a good topic for case discussion too, where students from the South could offer lessons to their counterparts in the North? I wonder if I was viewed in Europe not only as someone who had to be taught but also as someone they could learn from?

Studying in Europe or the US is viewed as superior to obtaining just a local degree in the Philippines. I certainly benefit from the colonial mentality in Filipino society. By sharing my stories and insights with colleagues, I have realised the lessons from these experiences. When I work with communities, I therefore resolve to engage people as partners for development rather than engage in unsustainable band-aid immersions. When I teach a global health course, I resolve to make sure that the challenges we discuss do not only focus on LMICs, and provide opportunities for students from the South to help solve the problems of the North. When I engage colleagues in global health, I resolve not to treat myself as better than the others just because of my European degree and learn to step back to highlight the expertise of many of my colleagues who have been trained locally. Finally, I have learned to view the West as an equal partner and no longer as superior to my own.- - HJL

Here we argue that reflexivity is incomplete with only self-understanding. Dialogues and action are equally important elements of the practice. Rather than a sporadic exercise, reflexivity must be a learnt habit with peers that develops into a culture of reflexivity in any global health organisation. We call on peers to build a culture of dialogical reflexivity in their institutions and translate their insights into collective action. We should take the rhetoric of transformation beyond academia, speak out and take action with all stakeholders, as long as we do not assume to do so on behalf of others. One can engage in a 
Box 2 Insights from my story as a British with mixed heritage

Born into a family of mixed ethnic heritage, I spent most of my life in the UK. From a young age I felt, but did not know how to articulate, the tensions that arose from having a white British mother and a father of Jamaican descent. When the British Empire ("how amazing!"), or more rarely, slavery ("disgusting") was discussed at school I was conscious of the internal tension that arose as a result of being taught to admire the successes of the Empire whilst feeling revulsion that one side of my heritage was responsible for commodifying the other.

There is no denying that racism is rife within the UK. Whilst the colour of my skin has at times been held against me, being British has also conferred many advantages, something I have a greater appreciation of, having spent the last six and half years living in Malaysia. Personally, my accent buys respect, my passport easy travel around the region. Professionally, my degrees from a bastion of British education have opened doors and created opportunities, opportunities that were critical when new and unestablished in the region. All this, despite the fact that one teacher told me l'd never get into said university because they "didn't accept people like me there." Why, I wondered? Was it because I am mixed-race? Came from a workingclass background on one side and immigrant on the other? Because I was female?!

Over the past year, the calls to decolonise global health increased in frequency in institutions in HICs at much the same time that the Black Lives Matter protests were taking place; no coincidence, I'm sure. The conversations on performative allyship with respect to antiracism prompted me to reflect on my position as a British researcher within a UN institution based in an LMIC. Did I fervently believe in our mandate to amplify the voices and work of researchers, practitioners, and communities from LMICs? Yes. Was I occupying a space that could be better filled by an individual from an LMIC? Maybe...

At first, these reflections led to a kind of paralysis, a certain sense of futility. Did I deserve to be where I was? Through conversations with colleagues, I started to unpack the guilt but also the frustration. Instead of focusing on what I couldn't change, I started to think about what I, as an individual, and we, as a global health institution, could do to decolonise our work. It means spending time talking to and working with colleagues from a range of LMICs to understand the nuances of what a decolonised global health could look like in their different contexts and given their different colonial, or non-colonial, histories. It is about not attempting to be the 'expert' or to speak 'for' anyone, but instead to use the platform that I/we have to create a space for discussion and debate and to ensure that voices of lived experience are prominent, indeed privileged, in all the work we lead or partner in. It acknowledges the richness that comes from varied perspectives and the need for experienced and early career practitioners' voices, in the diaspora and at home, and across geographies. It's still a work in progress, but I think that is kind of the point. A decolonised global health is not a tick box exercise. It will require concerted and continued effort to both make and maintain the change.-ER

debate on decolonising global health, but without ceding power in favour of marginalised voices and those with lived experience of coloniality to be heard, the desire to transform remains an intellectual exercise, or the decolonisation discourse itself ends up being colonised by the same privileged voices. Dialogical reflexivity with peers can provide the signposts towards meaningful action to decolonise both internally as individuals and structurally in the global health architecture. It is precisely the practice of reflexive dialogues with peers who critically engage with one another and demand accountability from one another ${ }^{3}$ that can serve as our shield from the danger of being neocolonial ${ }^{32}$ despite best intentions, or of falling into the trap of performative allyship. ${ }^{33}$

Finally, although our focus on reflexivity has emphasised the role of individuals, we do not in any way diminish the need for more political changes at the systems and structural levels. These changes will require radically reshaping the global health infrastructure and establishing more robust mechanisms to hold institutions into account. However, to actualise systemic transformation in global health, structural and individual changes are required because, ultimately, structures are maintained and can be transformed by people. We consider the potential of dialogical reflexivity with peers to sustain momentum for collective action and to facilitate a shared vision of a transformed global health future. The more we understand ourselves and our place in global health and the allies we have in this space, the more we become capable of transforming it. Reflexivity opens the opportunity for each one to tap into their relationships and networks and spread a transformative way of thinking and acting about global health. Reflexivity is not the panacea for global health, but by engaging peers through constant reflexive dialogues, we can walk together towards the transformation that we seek.

Twitter Harvy Joy Liwanag @harvylight and Emma Rhule @EmmaRhule

Acknowledgements We thank Professor Pascale Allotey and Dr Lavanya Vijayasingham for their insights which helped us improve this paper. This is part of a broader and ongoing conversation on decolonisation and transforming the future of global health both within UNU-IIGH and with stakeholders. We acknowledge our colleagues whose ideas during our dialogues with them may have been reflected one way or the other in our writing.

Contributors HJL and ER conceived the idea, wrote and edited subsequent drafts, and approved the final submission. HJL wrote the first draft.

Funding The authors have not declared a specific grant for this research from any funding agency in the public, commercial or not-for-profit sectors.

Competing interests None declared.

Patient consent for publication Not required.

Provenance and peer review Not commissioned; externally peer reviewed.

Data availability statement There are no data in this work.

Open access This is an open access article distributed in accordance with the Creative Commons Attribution Non Commercial (CC BY-NC 4.0) license, which permits others to distribute, remix, adapt, build upon this work non-commercially, and license their derivative works on different terms, provided the original work is properly cited, appropriate credit is given, any changes made indicated, and the use is non-commercial. See: http://creativecommons.org/licenses/by-nc/4.0/.

\section{ORCID iDs}

Harvy Joy Liwanag http://orcid.org/0000-0002-5609-3811

Emma Rhule http://orcid.org/0000-0002-6777-7645

\section{REFERENCES}

1 Stephenson J. Unequal access to COVID-19 vaccines leaves LessWealthy countries more vulnerable, poses threat to global immunity. JAMA Health Forum 2021;2:e210505. 
2 Ndumbe-Eyoh S, Muzumdar P, Betker C, et al. 'Back to better': amplifying health equity, and determinants of health perspectives during the COVID-19 pandemic. Glob Health Promot 2021;28:7-16.

3 Abimbola S, Asthana S, Montenegro C, Cortes CM, et al. Addressing power asymmetries in global health: imperatives in the wake of the COVID-19 pandemic. PLoS Med 2021;18:e1003604.

4 Büyüm AM, Kenney C, Koris A, et al. Decolonising global health: if not now, when? BMJ Glob Health 2020;5:e003394.

5 Hirsch LA. Is it possible to decolonise global health institutions? Lancet 2021;397:189-90.

6 Affun-Adegbulu C, Adegbulu O. Decolonising global (public) health: from Western universalism to global pluriversalities. BMJ Glob Health 2020;5:e002947.

7 Abimbola S, Pai M. Will global health survive its decolonisation? Lancet 2020;396:1627-8.

8 Hirsch LA. In the wake: interpreting care and global health through black geographies. Area 2020;52:314-21.

9 Khan M, Abimbola S, Aloudat T, et al. Decolonising global health in 2021: a roadmap to move from rhetoric to reform. BMJ Glob Health 2021;6:e005604.

10 Oti SO, Ncayiyana J. Decolonising global health: where are the southern voices? BMJ Glob Health 2021;6:e006576.

11 Chaudhuri MM, Mkumba L, Raveendran Y, et al. Decolonising global health: beyond 'reformative' roadmaps and towards decolonial thought. BMJ Glob Health 2021;6:e006371.

12 Pai M. Decolonizing Global Health: A Moment To Reflect On A Movement. Forbes [Internet], 2021. Available: https://www.forbes. $\mathrm{com} /$ sites/madhukarpai/2021/07/22/decolonizing-global-health-amoment-to-reflect-on-a-movement/ [Accessed 9 Aug 2021].

13 Nixon SA. The coin model of privilege and critical allyship: implications for health. BMC Public Health 2019:19:1637.

14 Lawrence DS, Hirsch LA. Decolonising global health: transnational research partnerships under the spotlight. Int Health 2020;12:518-23.

15 Mackean T, Fisher M, Friel S, et al. A framework to assess cultural safety in Australian public policy. Health Promot Int 2020;35:340-51.

16 Elliot ML. Critical Ethnographic Analysis of "Doing Good" on Short-Term International Immersion Experiences. Occup Ther Int 2015;22:121-30.

17 Fofana MO. Decolonising global health in the time of COVID-19. Glob Public Health 2021;16:1155-66.

18 Drexler S. The Unlikeliest Pandemic Success Story. The Atlantic [Internet], 2021. Available: https://www.theatlantic.com/international/ archive/2021/02/coronavirus-pandemic-bhutan/617976/ [Accessed 11 Feb 2021].

19 David EJR, Okazaki S. Activation and automaticity of colonial Mentality. J App/ Soc Psychol 2010:40:850-87.

20 Berger R. Now I see it, now I don't: researcher's position and reflexivity in qualitative research. Qualitative Research 2015:15:219-34.

21 Finlay L. "Outing" the researcher: the provenance, process, and practice of reflexivity. Qual Health Res 2002;12:531-45.

22 Probst B. The eye regards itself: benefits and challenges of reflexivity in qualitative social work research. Soc Work Res 2015;39:37-48.

23 Hankivsky O, ed. An intersectionality-based policy analysis framework. Vancouver, BC: Institute for Intersectionality Research and Policy, Simon Fraser University, 2012.

24 Nicholls R. Research and Indigenous participation: critical reflexive methods. Int J Soc Res Methodol 2009;12:117-26.

25 Pidgeon M. More than a checklist: meaningful Indigenous inclusion in higher education. Soc Incl 2016;4:77-91.

26 Krusz E, Davey T, Wigginton B, et al. What contributions, if any, can non-Indigenous researchers offer toward Decolonizing health research? Qual Health Res 2020;30:205-16.

27 Fanon F. The wretched of the earth. New York: Grove Press, 1963: 251.

28 Freire P. 1921-1997. Pedagogy of the oppressed [Internet. New York: Continuum, 1972. https://search.library.wisc.edu/catalog/ 999895194802121

29 Ngũgĩ T. Decolonising the mind : the politics of language in African literature. London: Heinemann, 1986: 114.

30 Tuhiwai Smith L. Decolonizing Methodologies [Internet]. London: Zed Books, 1999: 208. https://www.bloomsbury.com/us/decolonizingmethodologies-9781786998132

31 Tuck E, Yang KW. Decolonization is not a metaphor. Decolonization: Indigeneity, Education \& Society, 2012. https://jps.library.utoronto. ca/index.php/des/article/view/18630

32 Guinto R. \#DecolonizeGlobalHealth: Rewriting the narrative of global health [Internet], 2019. Available: https://www.internationalhealthp olicies.org/decolonizeglobalhealth-rewriting-the-narrative-of-globalhealth/

33 Phillips H. Performative Allyship Is Deadly (Here's What to Do Instead) [Internet]. Forge, 2020. Available: https://forge.medium. com/performative-allyship-is-deadly-c900645d9f1f [Accessed $29 \mathrm{Jul}$ 2021]. 